\title{
Some considerations about Ångström exponent distributions
}

\author{
F. Wagner ${ }^{1}$ and A. M. Silva ${ }^{1,2}$ \\ ${ }^{1}$ Centro de Geofísica, Évora, Portugal \\ ${ }^{2}$ Universidade de Évora, Departamento de Física, Évora, Portugal
}

Received: 19 June 2007 - Published in Atmos. Chem. Phys. Discuss.: 30 August 2007

Revised: 10 December 2007 - Accepted: 30 December 2007 - Published: 5 February 2008

\begin{abstract}
A simulation study has been performed in order to show the influence of the aerosol optical depth (AOD) distribution together with the corresponding error distribution on the resulting Ångström exponent (AE) distribution. It will be shown that the Ångström exponent frequency of occurrence distribution is only normal distributed when the relative error at the two wavelengths used for estimation of the Ångström exponent is the same. In all other cases a shift of the maximum of the AE-distribution will occur. It will be demonstrated that the Ångström exponent (or the maximum of an AE distribution) will be systematically over- or underestimated depending on whether the relative error of the shorter wavelength is larger or smaller compared with the relative error of the longer wavelength. In such cases the AE distribution are also skewed.
\end{abstract}

\section{Introduction}

The Ångström exponent is a widely used parameter in atmospheric sciences dealing with optical properties of aerosol particles. Since the early publications of Ångström (Ångström, 1929 and 1930) and his later publications (Ångström, 1961 and 1964), where this parameter was mainly applied to the description of the spectral behavior of the atmospheric extinction and transmission, respectively, it is now also applied to a variety of similar but slightly different optical properties, for instance to the atmospheric scattering or backscattering coefficients.

The Ångström exponent is very popular because of the simplicity of the respective equation, because it enables to interpolate or to extrapolate aerosol optical properties, and because it is connected to particle microphysics (related with

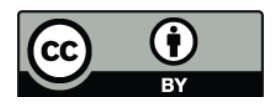

Correspondence to: F. Wagner (frankwagner@uevora.pt) the mean size of aerosols) as it describes, approximately for a certain radius range, a power law (Junge) aerosol size distribution. The latter was refined by O'Neill and Royer (1993) who derived bimodal size distribution radii using Ångström exponents.

With the upcoming of automated measuring devices and automated data evaluation procedures huge data sets are created which cannot be handled any more by detailed individual analysis. As an alternative a statistical approach is often used. Also error analysis for each single measurement is not practical or not even possible for large datasets. Since the data are all collected in the same manner it is reasonable to assume that, except for time dependent systematic errors, the individual measurement errors are more or less the same and individual error analysis would give no additional information. In such cases a mean error instead of single errors is given in the literature.

It should be pointed out that the phrase "large datasets" implies that several calibration constants were applied to the data. It is recommended by e.g. Verein Deutscher Ingenieure (VDI, 1994) to calibrate a sun photometer every year. Many scientists as well as networks (e.g. AERONET) try to follow this recommendation. Consequently long time series of AOD for a single station were treated with several different calibration constants including an interpolation in time of these constants. As it will be explained later the error of the calibration constant will propagate as bias in the calculation of AOD. The use of several calibration values inside a database will result in AOD errors with positive and negative signs as well as with different magnitudes. Furthermore Campanelli et al. (2007) showed that the calibration constant itself varies on a daily basis which means that the resulting AOD-error may also vary daily.

In sun photometry the error of the $\operatorname{AOD}(\Delta \tau)$ is often given as an absolute value. Holben (1998) and Eck (1999) gave errors for the AERONET AOD measurements of 0.02 for shorter wavelengths $(<440 \mathrm{~nm})$ and of 0.01 for longer

Published by Copernicus Publications on behalf of the European Geosciences Union. 
wavelengths ( $>440 \mathrm{~nm})$. Knobelspiesse et al. (2004) mentioned that the error of the AOD depends only slightly on the AOD value itself and they gave absolute errors between 0.021 and 0.010 for the AOD derived from SIMBAD and 0.015 derived from Microtops sun photometer measurements. In contrast the error corresponding to the AOD derived from satellite measurements consists of an absolute part and a relative part. Remer et al. (2005) showed that the error of the AOD at $550 \mathrm{~nm}$ corresponding to MODIS retrievals over ocean is $\Delta \tau=0.03 \pm 0.05 \tau$ and $\Delta \tau=0.05 \pm 0.15 \tau$ over land.

These errors are reported for well-calibrated and maintained instruments. On the other hand Smirnov and coworkers (2000) reported that in harsh environments, e.g. Barbados, which results in rapid filter degradation, the errors could increase. Cachorro et al. (2004) pointed out that an inaccurate calibration will lead to a diurnal cycle of the AOD and would result in significant AOD errors at the miscalibrated wavelength under very clean conditions which can be observed at mountain stations. Such errors can be as large as $100 \%$.

Measurements over several years taken within automated networks result in the existence of large datasets. Depending on the location of the monitoring station the data varies due to the observation of different aerosol types with different optical and microphysical properties. But even in the case that only one single aerosol type would be present the AOD measurements varies due to different source strengths. For example, in the case of sea salt aerosols, they depend on the wind velocity as well as on the change of relative humidity, which leads to an alteration of particle size and a small alteration in the refractive index, both resulting in changed optical properties. Smirnov et al. (2003) showed the effect of wind speed on columnar aerosol optical properties for sea salt, and Wai and Tanner (2004) on sea salt concentrations in $\mathrm{PM}_{10}$ measurements. An example for a parameterized aerosol source function, which mainly depends on the wind speed, is given in Gong et al. (2003) and Zhang et al. (2005) describing the dependency of sea-salt emissions on the relative humidity.

The analysis of such large data sets is often done in terms of frequency distributions of the AOD and of the Ångström exponent in order to determine mean aerosol properties. O'Neill et al. (2000) reported that the AOD frequency distribution often follows a logarithmic normal distribution and the Ångström exponent frequency distribution often follows a normal distribution. Knobelspiesse et al. (2004) used logarithmic normal distributions for AOD and normal distributions for the Ångström exponent in order to classify their measurements into several groups. In contrast Tahnk and Coakley (2002) showed in an investigation for the Indian Ocean and Arabian Sea that frequency distribution of AOD for a region is well represented by a Gamma distribution.

This paper deals with AOD distributions and some consequences on retrieved Ångström exponent frequency distributions when normal distributed errors are taken into account and the relative errors of the AOD at two different wavelengths differs. We restrict the analysis only to two wavelengths, even being aware that a regression through the data measured at multiple wavelengths would reduce the overall error. This restriction is justified because first not all kinds of sun photometers have a suficient amount of channels for the retrieval of an Ångström exponent using multiple wavelengths. Second, as mentioned above, the analysis can be transferred to different instruments dealing with optical data, such as scattering (e.g. measured with a nephelometer) or backscattering coefficient (determined by lidar), from which an Ångström exponent is also commonly derived, although only based on optical data at two wavelengths.

Conventional error propagation will be briefly presented in Sect. 2. The methodology for the simulation will be described in Sect. 3 and the results will be given in Sect. 4 and finally conclusions will be presented in Sect. 5 .

\section{Error propagation}

The wavelength dependency of the extinction coefficient or of the optical depth can be described in terms of the socalled Ångström exponent (AE). The relationship between two wavelengths is expressed via the following formula (see e.g. Ångström (1964):

$\tau=\beta \lambda^{-\alpha}$

where $\lambda$ is wavelength in microns, $\tau$ is the optical depth of particles or molecules, $\alpha$ the Ångström exponent. The parameter $\beta$ is the Ångström turbidity coefficient. It is equal to the AOD at 1 micron and corresponds to the particle load. For molecules the Ångström exponent is about 4 and varies between about 0 and 2 for particles. In case the AE is derived from measurements of optical data of atmospheric aerosols $\alpha$ as well as $\beta$ depend on the wavelength range used for the calculation because the Ångström law is only an approximation of the spectral dependency of the extinction coefficient or of the AOD. Various studies showed this dependency and a nice overview as well as a comparison of different calculation methods is given by Kaskaoutis and Kambezidis (2008).

Measurements at two different wavelengths allow the experimental determination of $\alpha$ according to:

$$
\begin{aligned}
& \frac{\tau_{1}}{\tau_{2}}=\left(\frac{\lambda_{1}}{\lambda_{2}}\right)^{-\alpha} \text { and further }: \frac{\ln \left(\frac{\tau_{1}}{\tau_{2}}\right)}{\ln \left(\frac{\lambda_{1}}{\lambda_{2}}\right)}=-\alpha \\
& \text { or } \frac{\ln \tau_{1}-\ln \tau_{2}}{\ln \lambda_{1}-\ln \lambda_{2}}=-\alpha
\end{aligned}
$$

The usual maximum error for the Ångström exponent can be derived via error propagation. Under the assumption that each wavelength is exactly known, or that the error for the 
wavelengths is negligible, it follows from error propagation law

$\Delta \alpha=\left|\frac{\partial \alpha}{\partial \tau_{1}}\right| \Delta \tau_{1}+\left|\frac{\partial \alpha}{\partial \tau_{2}}\right| \Delta \tau_{2}$

that:

$$
\Delta \alpha=\frac{1}{\ln \left(\frac{\lambda_{2}}{\lambda_{1}}\right)}\left(\frac{\Delta \tau_{1}}{\tau_{1}}+\frac{\Delta \tau_{2}}{\tau_{2}}\right)
$$

The latter equation is quite similar to the one derived by Hamonou et al. (1999), whereas Hamonou et al. focused on the main error in sun photometery, the calibration error, and here all different kinds of errors in AOD are included. The wavelength range in sun photometry is usually between 340 and $1020 \mathrm{~nm}$ and for lidar it is usually between 355 and $1064 \mathrm{~nm}$. The factor $1 /\left(\ln \left(\lambda_{2} / \lambda_{1}\right)\right.$ is equal to 1 for a wide wavelength pair, e.g. for the wavelengths 1020 and $375 \mathrm{~nm}$, and 2 for a narrow wavelength pair, e.g. for 870 and $527 \mathrm{~nm}$. These two wavelengths ranges have practically relevance because they are similar to the various wavelength pairs used in the literature for the retrieval of the Angström exponent. For instance Hamonou et al. (1999) used the wavelength pair 443 and $670 \mathrm{~nm}$. Anderson et al. (2005) used the wavelengths pairs 550 and $675 \mathrm{~nm}$ for the MODIS retrievals of the Ångström exponent over ocean and 440 and $670 \mathrm{~nm}$ over land. AERONET provides several Ångström exponents, e.g. calculated from the AOD at 500 and 870 or at 440 and $870 \mathrm{~nm}$ among others. It should be mentioned here that AERONET uses all available measurements in a certain wavelength range and determines the $\mathrm{AE}$ via linear regression thereby reducing the errors that occur relative to the use of only two wavelengths. On the other hand, Gobbi et al. (2007) used pairs of the AERONET measurements in this wavelength range (440-675 nm and $675-870 \mathrm{~nm}$ ) to access the curvature of the Ångström exponent.

With an error of 0.02 for the AOD measurements at the short wavelength (e.g. $440 \mathrm{~nm}$ ) and of 0.01 at the long wavelength (e.g. $870 \mathrm{~nm})$ it follows that for clean optical conditions with an AOD at $440 \mathrm{~nm}$ of 0.06 the maximum error for the Ångström exponent $\Delta \alpha=1.17$ and for hazy conditions with AOD at $440 \mathrm{~nm}$ of 0.4 is $\Delta \alpha=0.17$ assuming an underlying Ångström exponent of 1.5. These values drop down to 0.73 and 0.11 , respectively, if the Ångström exponent is 0 . The error decreases further if only measurements at larger airmasses will be used.

The maximum error derived with Eq. (4) cannot explain any Ångström exponent frequency distribution which is often observed for large data sets. Error propagation always looks for the maximum error and does not take into account the "shape" of distributions including possible occurrences of skewness or kurtosis. Furthermore it can not explain because of the symmetry in the equation - systematic shifts whereas the direction of the shift depends on at which wavelengths the relative error is larger or smaller. It will be shown later that the Ångström exponent will be systematically overor underestimated depending on whether the relative error of the shorter wavelength is larger or smaller compared with the relative error of the longer wavelength.

\section{Methodology}

A simulation study has been performed in order to show the influence of the AOD distribution together with the corresponding error distribution on the resulting Ångström exponent distribution.

Hereafter the AOD distribution is modeled as logarithmic normal distribution, which is e.g. observed by O'Neil (2000) or by Smirnov et al. (2000) for daily values. The simulated error follows a normal distribution (Gaussian error) whereas the errors at the two wavelengths are treated independently, each with its own amplitude and standard deviation. The use of a normal distributed error function can be justified by the application to large datasets. For a single AOD measurement the main error is introduced by the calibration error which leads to either too high or too low AOD values and the magnitude depends on the airmass factor. However the values in large databases were obtained by applying different calibration constants to measurements from different times or for different instruments. As already mentioned a yearly recalibration of the instrument is recommended. The value of a calibration constant is usually linear interpolated between 2 subsequent calibrations. Under the assumption that the calibration constant changes smoothly in time this procedure should reduce the actual error of the calibration constant for the time periods when no real calibration is available. Furthermore in all cases where the differences between the used calibration constant and "true" value of the calibration constant changes sign for 2 subsequent calibrations the interpolation procedure guarantees that there will be a measurement interval with errors close to zero. Hence the occurrence of small errors has higher probability than the occurrence of large errors. Consequently all kinds of errors (with positive or negative signs as well as different magnitudes) will be found. Additionally as mentioned above there exists a certain day to day variability in the calibration constant as shown by Campanelli et al. (2007). Comparing the actual (daily) calibration value with the value determined via the interpolation procedure one can see that the difference of both values and hence the error changes its sign over short time scales.

The comments above support an error distribution function for AOD which contains positive and negative values and with a higher frequency of occurrence of small errors than of large errors. This general error distribution is further modified by several other small factors: the solar constant varies not only over the well-known 11 year cycle but also over small time scales, see e.g. Fröhlich and Anklin (2000); instrumental errors (e.g. instrumental noise, temperature variations, pointing error etc.) and Rayleigh correction depending 
on the presence of high and low pressure systems (see comment to this manuscript by Wehrli) which becomes increasingly important with decreasing AOD.

Therefore we think that any error distribution which is more or less symmetric and has a maximum around an error value of zero may be used for the simulations. In our case a normal distribution was considered which has also an additionally important feature: it can explain why some Ångström exponent histograms, as reported in the literature, can be approximated by normal distributions.

In the first part of the simulations the normal distribution errors were cut at one standard deviation (1 sigma). Consequently only $68 \%$ of the Gaussian distributions were taken into account and the remaining wings $(32 \%)$ were ignored. This procedure introduces to the resulting Ångström exponent distribution some small features which would vanish if the complete normal distribution (defined between $+/-$ infinity) would be used. However the main qualitative features remain nearly unchanged. Finally it should be mentioned here that due to the logarithm of the optical depth in the Angström exponent equation (see Eq. 2) it is not possible to take the whole Gaussian error function into account. For values of $\tau-|\Delta \tau|<0$ the logarithm (see Eq. 1) is not defined, or in other words due to the positive nature of the optical depth the Gaussian error function is in reality only an approximation and cannot be true even under ideal conditions.

In order to simulate frequency of occurrence distributions different class numbers were considered for all distributions. The AOD lognormal distributions were divided into 6000 classes and modeled for AOD's between 0 and 3. The error normal distributions were divided into 2000 classes whereas the minimum and the maximum depend on the given standard deviation (sigma). Finally the resulting Ångström exponent distributions were calculated between -2 and +4 .

The simulations were performed as follows:

1) Select randomly an optical depth class for the first wavelength.

2) Calculate - according to the given Ångström exponent - the optical depth of the second wavelength.

3) Select randomly an error class for the error frequency distribution of the first wavelength and add this error (error1) to the selected AOD of the first wavelength.

4) Select randomly an error class for the error frequency distribution of the second wavelength and add this error (error2) to the selected AOD of the second wavelength.

5) Finally calculate the resulting Ångström exponent and sort it into one of the 6000 classes.

This procedure is repeated 4000000 times, in order to have a sufficient number of Ångström exponents to determine the resulting Ångström exponent distribution. Rounding numerical errors lead to some scattering in the Ångström exponent distribution.

\section{Results}

In the simulations the absolute error (distribution) is independent of the AOD. Any given relative error refers always to the mode value (maximum value) of the AOD frequency distribution. This is applied in Fig. 1 for errors of $\Delta \tau=0.02$ at a short wavelength (either $\lambda=340$ or $440 \mathrm{~nm}$ ) and $\Delta \tau=0.01$ at a long wavelength (either $\lambda=870$ or $1020 \mathrm{~nm}$ ). If the given relative error at one wavelength is fixed then the relative error at the other wavelength depends on the underlying Ångström exponent. The relative errors at both wavelengths are equal at an Ångström exponent which corresponds to the AE obtained from the errors themselves. Depending on the wavelength range used, the Angström exponent varies between 0.63 (pair $340 \mathrm{~nm}$ and $1020 \mathrm{~nm}$ ) and 1.02 (pair $440 \mathrm{~nm}$ and $870 \mathrm{~nm})$.

\subsection{Equal relative errors}

Figure 2 shows the Ångström exponent distribution for different relative errors if the relative errors are identical at both wavelengths. In Fig. 2a the width of the lognormal AOD distribution was fixed and only the relative error was modified. It can be clearly seen that with increasing relative error the Ångström exponent distribution becomes broader and the maximum is less pronounced. In all cases the maximum corresponds to the underlying Ångström exponent (0). This behavior is independent of the underlying Ångström exponent (not shown) and of the AOD but it depends on the width of the logarithmic normal distribution. Figure $2 b$ shows this dependency for the relative error of $100 \%$. A larger value of sigma corresponds to a higher amount of large AOD's in the AOD distribution. Because the given error corresponds to the AOD at the maximum of the AOD frequency distribution and due to the fact that the absolute error is constant for all AOD's, the relative error at larger AOD's is smaller. Consequently for narrow AOD distributions the corresponding Ångström exponent distribution is broader. Furthermore, in this case of equal relative errors, the Angström exponent distributions are symmetric (no skewness). It should be mentioned that the kurtosis seen in Fig. 2 is mainly an artifact due to the cutting of the wings of the normal distributed error function. The kurtosis becomes less pronounced if the calculations are performed until 2 or 3 sigma.

\subsection{Unequal relative errors}

Figure $3 \mathrm{a}+\mathrm{b}$ show the resulting Ångström exponent distributions if the two relative errors are different at the two wavelengths. In contrast to the previous figure the resulting Ångström exponent distributions are no longer symmetric. They show certain skewness and the maximum is shifted. The shift is larger when the relative errors at both wavelengths are very different and smaller when the relative errors are similar. If the relative error at the first wavelength 
Table 1. Relative errors for the case of an absolute error of 0.02 at $340 \mathrm{~nm}$ and 0.01 at $1020 \mathrm{~nm}$ (1 Sigma).

\begin{tabular}{lllll}
\hline $\begin{array}{l}\text { AOD } \\
\text { @340 nm }\end{array}$ & $\begin{array}{l}\text { Rel. Error (\%) } \\
\text { @340 nm }\end{array}$ & $\begin{array}{l}\text { Ångström } \\
\text { Exponent }\end{array}$ & $\begin{array}{l}\text { AOD } \\
\text { @ 1020 nm }\end{array}$ & $\begin{array}{l}\text { Rel. Error (\%) } \\
\text { @ 1020 nm }\end{array}$ \\
\hline 0.2 & 10 & 0.0 & 0.20 & 5 \\
0.2 & 10 & 0.5 & 0.12 & 9 \\
0.2 & 10 & 1.0 & 0.07 & 15 \\
0.2 & 10 & 1.5 & 0.04 & 26 \\
0.2 & 10 & 2.0 & 0.02 & 45 \\
\hline
\end{tabular}

is larger than the one at the second wavelength then the Ångström exponent distribution is shifted to higher values and vice versa. Again the Ångström exponent distributions are narrower when the AOD distributions are broader, i.e. contains a relatively higher amount of larger AOD's. The bend and the kurtosis visible in the figures are an artifact caused by the wing cutting of the error function.

The reason for the shift lies in the multiplicative nature of relative errors. This can be illustrated for a single relative error with the following equations, although for an error distribution the same can be observed. Let $\varepsilon$ denote the relative error. If the relative errors are equal at both wavelengths, i.e. $\varepsilon_{1}=\varepsilon_{2}=\varepsilon$, then the error in the Ångström exponent cancels out according to:

$\frac{\ln \left(\frac{\left(1+\varepsilon_{1}\right) \tau_{1}}{\left(1+\varepsilon_{2}\right) \tau_{2}}\right)}{\ln \left(\frac{\lambda_{1}}{\lambda_{2}}\right)}=\frac{\ln \left(\frac{(1+\varepsilon) \tau_{1}}{(1+\varepsilon) \tau_{2}}\right)}{\ln \left(\frac{\lambda_{1}}{\lambda_{2}}\right)}=\frac{\ln \left(\frac{\tau_{1}}{\tau_{2}}\right)}{\ln \left(\frac{\lambda_{1}}{\lambda_{2}}\right)}=-\alpha$

In case of different relative errors $\varepsilon_{1} \neq \varepsilon_{2}$ the term

$\frac{\left(1+\varepsilon_{1}\right)}{\left(1+\varepsilon_{2}\right)}$ differs from unity which corresponds to a shift in the Ångström exponent. If $\varepsilon_{1}>\varepsilon_{2}$ the Ångström exponent becomes larger and becomes smaller if $\varepsilon_{1}<\varepsilon_{2}$. This confirms the findings of our simulations.

Remembering Fig. 1 where, for a constant absolute value and a fixed relative error of the AOD at one wavelength the relative error at the second wavelength depends on the underlying Ångström exponent, it can be concluded here that, in practice, the shift of the maximum of Ångström exponent distribution can go in both directions depending on the underlying true Angström exponent. This means that when the same (identical) instrument is monitoring different aerosol types (i.e. different Ångström exponents) over a long time period, the resulting AE-distribution can have either a shift of the maximum towards smaller Ångström exponents corresponding to one aerosol type or a shift towards larger Ångström exponents corresponding to another aerosol type.

It is therefore necessary - before analyzing Ångström exponent distributions - to restrict the analysis to AOD values which are sufficiently higher than the correspondent error. The meaning of "sufficiently higher" depends on geometric standard deviation of the AOD distribution. Our results indicate that an error up to $50 \%$ can be accepted in cases of a wide AOD-distribution whereas the error should not exceed

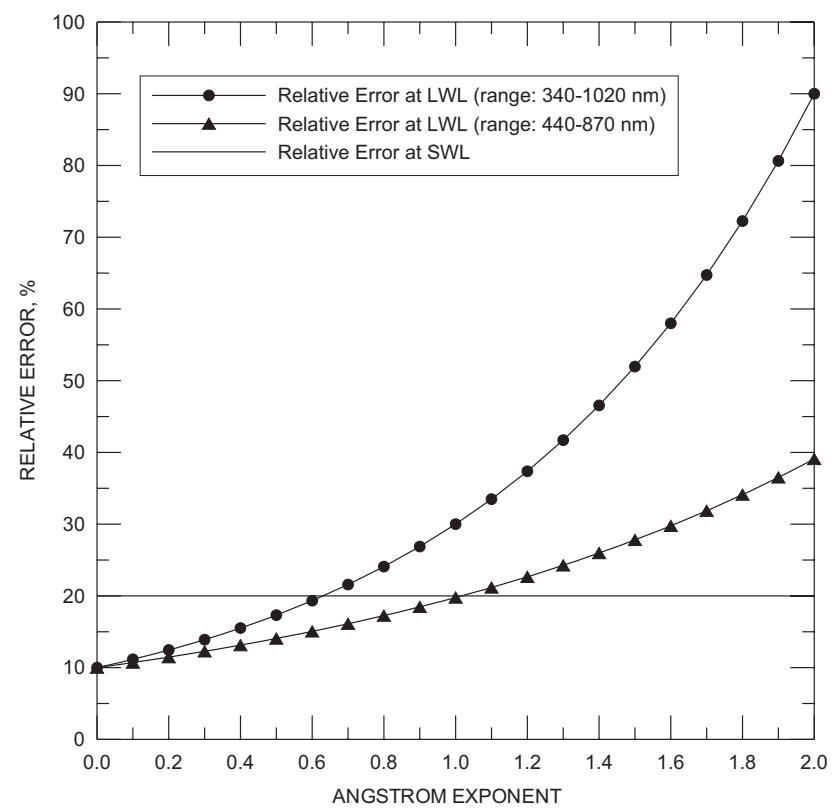

Fig. 1. Relative error at the longer wavelength (LWL) as a function of the Ångström exponent when the relative error at the shorter wavelength (SWL) is $20 \%$. Two different wavelengths ranges are shown. Used values for the calculation: AOD @ $\mathrm{SWL}=0.1$, error @ SWL=0.02, error @LWL=0.01.

$30 \%$ for a narrow AOD-distribution. Such a restriction was already used by Gobbi et al. (2007) who classified aerosol properties using $\mathrm{AE}$ for $\mathrm{AOD}$ values larger the 0.15, only.

\subsection{Application to measurements for well maintained sun photometers}

Now the simulations will be calculated for typical AOD conditions and for the typical errors for well maintained sun photometers. The wavelength pair 340 and $1020 \mathrm{~nm}$ was used and the mode optical depth at $340 \mathrm{~nm}$ was taken which corresponds to clean or medium turbid conditions according to common situations at the measuring site. The Ångström exponent varied between 0.0 and 2.0 and the optical depth at $1020 \mathrm{~nm}$ could be determined. The geometric standard deviations of the AOD distribution were considered to be 1.1, 1.5 and 2.0. The error was simulated as Gaussian error with a mean value of 0.02 at $340 \mathrm{~nm}$ and 0.01 at $1020 \mathrm{~nm}$. 

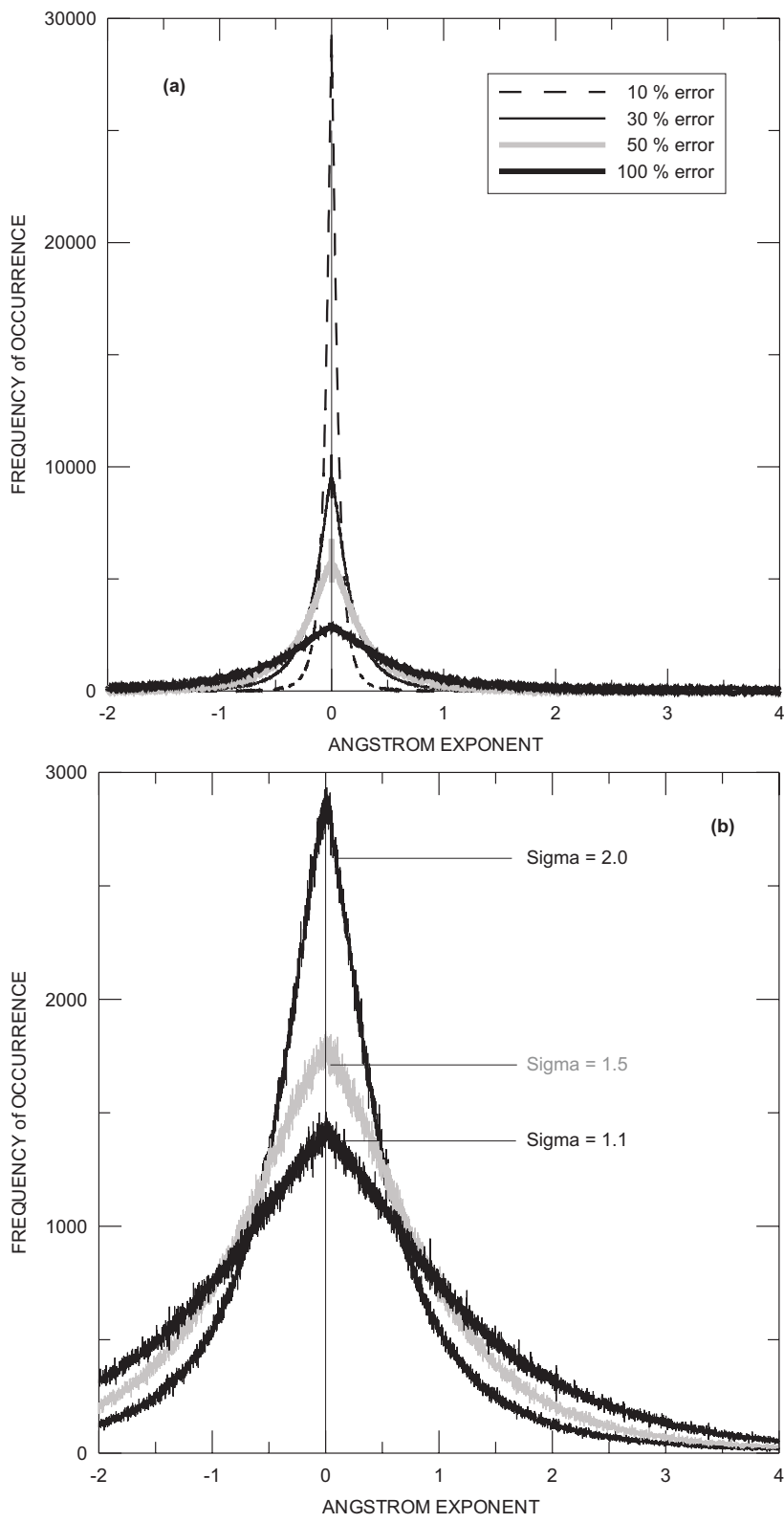

Fig. 2. Ångström exponent distribution for the case of equal relative errors at both wavelengths and an underlying Ångström exponent of 0 ; (a): dependency on the relative error values for the same AODdistribution; (b): dependency on AOD-distributions with different geometric standard deviations (sigma) for the case of relative errors of $100 \%$ at both wavelengths.

The corresponding relative error for 1 sigma is given in Table 1. The retrieved Ångström exponent frequency distribution of all these simulations is shown in Fig. 4.

With increasing underlying Ångström exponent the maximum of the AE-distribution became smaller, the distribution itself became wider and a shift in the maximum occurred. The reason for this is that with increasing underlying Ångström exponent the AOD at $1020 \mathrm{~nm}$ was smaller and therefore the relative error increased. A larger error corresponds to a wider distribution which in turn demands a lower maximum. Furthermore because the difference of the relative errors at the two wavelengths changes with the given Ångström exponent (which corresponds to a change in AOD, see Table 1) the amount of the shift of the maximum of the Ångström exponent distribution also changes. With increasing differences of the relative errors the shift becomes larger. A closer look shows that in fact the shift in the maximum changed direction at an Ångström exponent of about 0.5. No shift would occur at exactly an Ångström exponent of 0.631 according to the Ångström exponent of the errors itself (compare Fig. 1).

Such a behavior is especially pronounced for a narrow AOD distribution (sigma $=1.1$ ). This is illustrated in Fig. 5 where the deviation of the simulated Ångström exponent distribution from the given Ångström exponent is shown. In contrast to the previous part the error distribution was now simulated with $+/-2$ standard deviations.

In the same figure two Gaussian normal distributions adapted to the respective $\mathrm{AE}$ distribution are also represented. The Ångström exponent distribution for an $\mathrm{AE}$ of 0.5 , which nearly corresponds to equal relative errors, resembles very much a Gaussian distribution. In fact for an $\mathrm{AE}$ of 0.631 the relative errors would be $10 \%$ at both wavelengths and the Ångström exponent distribution would really follow a Gaussian normal distribution. In contrast, the $\mathrm{AE}$ distribution for an $\mathrm{AE}$ of 2.0 (maximum difference in the relative errors) is no longer normal distributed. It shows a certain asymmetry which corresponds to a certain skewness. It should be noted that the kurtosis and the bends are nearly absent which confirms the comments given above that this effect is introduced into the simulations by cutting the wings of the error normal distributions.

The relevancy of these findings depends strongly on the predominant particle population and on the weather conditions which exists at the measuring site. There exist several stations belonging to the AERONET network and other stations belong to GAW (Global Atmospheric Watch) which report very low AOD. These are mainly stations located on islands or mountains. However also at other locations, often but not exclusively situated in a rural environment, sometimes low AOD values are reported. An example is Palaiseau, France where an AOD's as low as 0.107 at $340 \mathrm{~nm}, 0.111$ at $380 \mathrm{~nm}$ and 0.016 at $1020 \mathrm{~nm}$ as daily average was observed on 8 November 2005. Given the constant errors of 0.02 for the short wavelength and 0.01 for the long wavelength the relative errors for the latter measurement site are $19 \%$ at $340 \mathrm{~nm} 18 \%$ at $380 \mathrm{~nm}$ and $63 \%$ at $1020 \mathrm{~nm}$, respectively. This is a large asymmetric error which corresponds well to the investigation of this publication.

Aerosol optical depth and hence the Ångström exponent derived from satellite measurements have usually a higher error than the same quantities derived from ground-based measurements. In particular it is expected that Ångström 

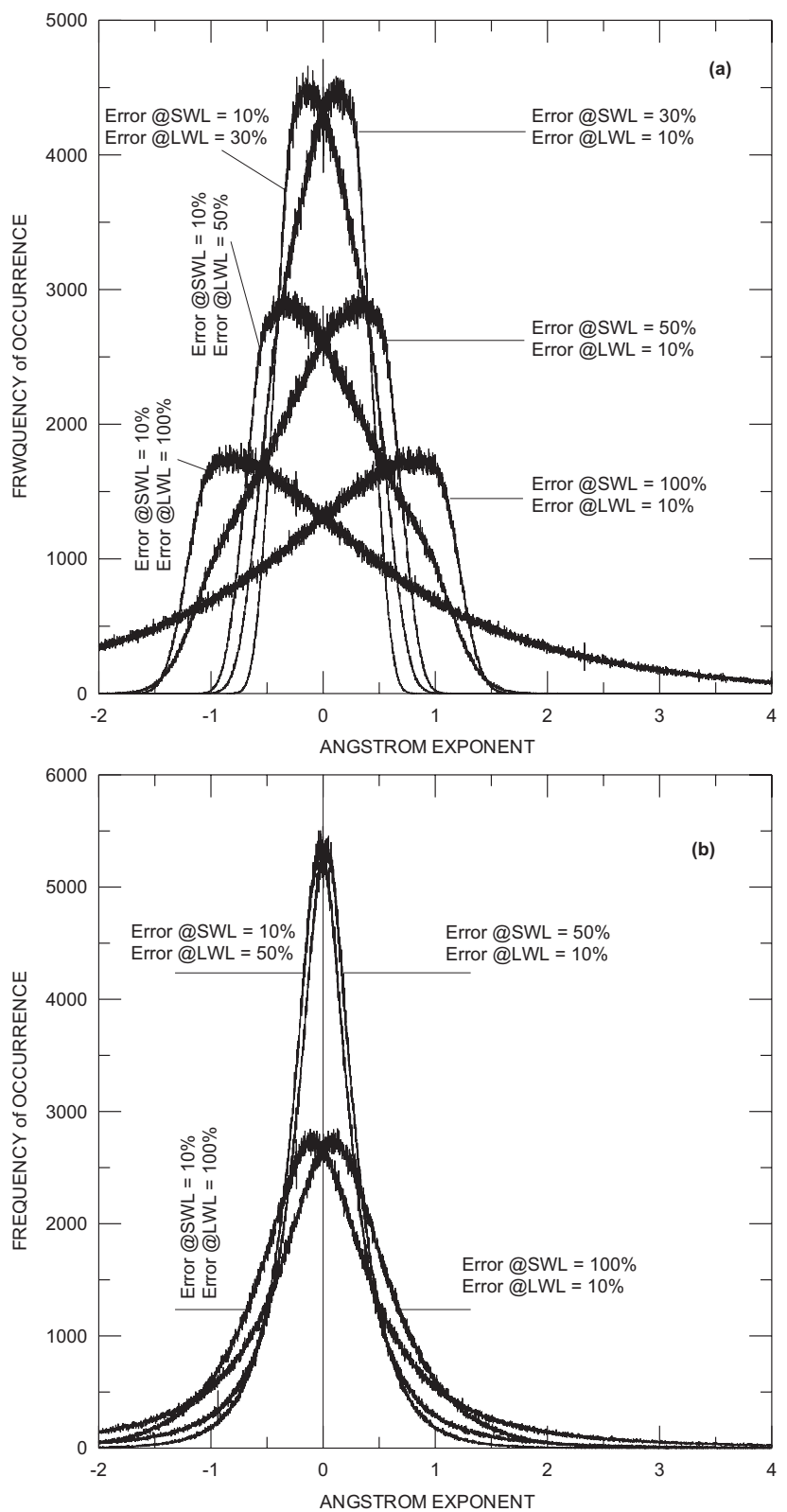

Fig. 3. Ångström exponent distribution for the case of different relative errors at both wavelengths and an underlying Ångström exponent of 0 in dependency on the values of the two relative errors; SWL denotes the shorter wavelength and LWL the longer wavelength, respectively. (a) for a sigma of 1.1 in the AOD distribution and (b) for a sigma of 2.0 in the AOD distribution. The case of error $1=30 \%$ and error $2=10 \%$ is not shown in (b) because the two curves could not be distinguished.

exponents derived over oceanic areas may be highly uncertain because the AOD are, for certain conditions, normally very low (Ignatov et al., 1998, and Voss et al., 2001). Furthermore, the results of our simulation study should not be applied to satellite measurements because the retrieval process of AOD's and AE's from satellite measurements is always

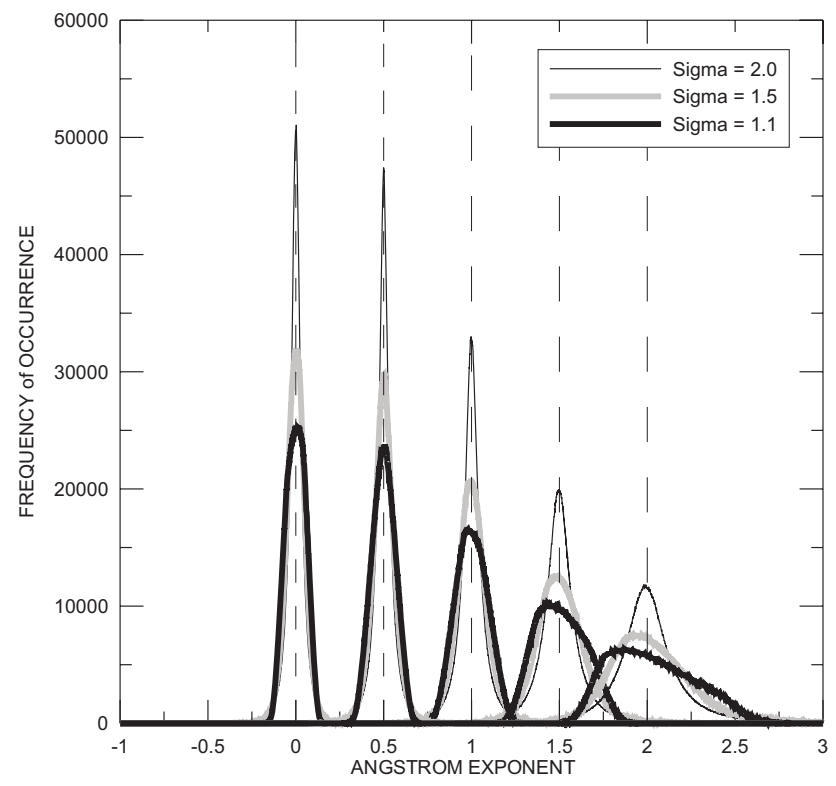

Fig. 4. Ångström exponent distributions based on AOD distributions with different geometric standard deviations (sigma) and several underlying Ångström exponents (dotted lines) calculated with a constant optical thickness of 0.2 at $340 \mathrm{~nm}$ and a constant error of 0.02 at $340 \mathrm{~nm}$ and 0.01 at $1020 \mathrm{~nm}$.

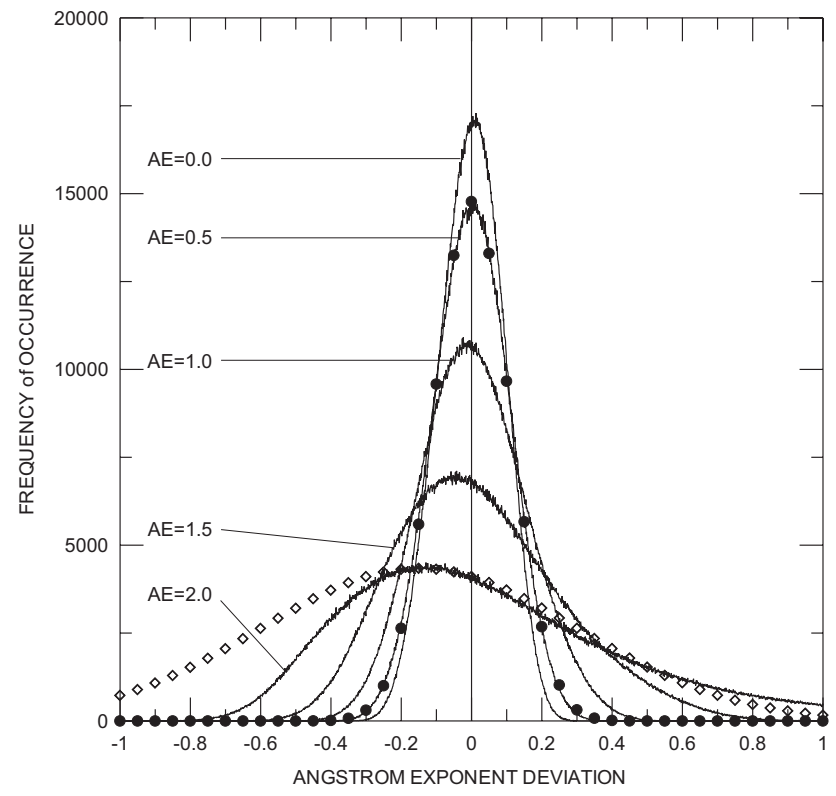

Fig. 5. Deviation of the Ångström exponent calculated for different Ångström exponents (AE) with a constant optical thickness of 0.2 at $340 \mathrm{~nm}$, a narrow AOD distribution (sigma=1.1) and constant errors of 0.02 at $340 \mathrm{~nm}$ and 0.01 at $1020 \mathrm{~nm}$. The calculations were performed with error of $+/-2$ sigma. The two curves with symbols represent a Gaussian normal distribution.

based upon an aerosol model therefore the AOD's at different wavelengths are not independent and the AE's depend on the underlying aerosol model. 
The problem with the shift in the Ångström exponent is more relevant for very narrow AOD distributions. Such narrow distributions can only occur when the atmosphere is stable over a longer time. However, under such conditions it is possible to average the measured AOD's before calculating the Ångström exponent in order to reduce the measurement uncertainty. With a changing atmosphere it is not clear if such an averaging is justified, because under practical conditions it will be usually difficult to decide whether the aerosol population has changed. A more effective way in reducing uncertainties is to restrict the analysis to larger airmasses. With increasing airmass $m$ the error due to the calibration uncertainty decreases with a factor $1 / \mathrm{m}$ as already shown out by Hamonou et al. (1999) or Cachorro et al. (2004). However special attention is needed with respect to how much data around noon should be excluded in order not to violate any temporal statistical analysis of a large dataset containing automatic measurements. For instance if one would restrict an investigation to airmasses larger than 2 , then in turn the calibration error would be cutted in half. The advantage of having a smaller error would be achieved at the costs of temporal representation of the measurements. For a station located in the Southern Europe, all data observed during winter time would be included in the analysis, whereas, during summer time, all data between 08:00 a.m. and 04:00 p.m. would be excluded.

\subsection{Summary of the results}

The results may be summarized as follows:

1) The calculations have shown that for a given lognormal AOD-distribution combined with a normal error distribution the resulting Ångström exponent distribution is normal distributed only in the case of equal relative errors.

2) When the AOD frequency distribution is wide (e.g. sigma=2) then the resulting Ångström exponent frequency distribution is narrower in comparison with a narrow AOD-distribution (e.g. sigma=1.1). The reason for this is due to the fact that the error is given with respect to the mode mean and a wider AOD distribution has a larger portion of higher AOD values then a narrower AOD distribution. This results in a higher portion of small relative errors and thus in a narrower Ångström exponent distribution.

3) If the mean AOD is high (e.g. 0.4) the Ångström exponent frequency distribution is narrower as for low turbidity values (e.g. 0.06) in case of identical absolute errors. The reason is that the relative error becomes smaller when the absolute error is fixed and the AOD increases.
4) If the relative errors at both wavelengths are equal, or in a practical sense similar, then the peak or maximum of the Angström exponent distribution reflects the true value, otherwise a shift either to smaller or to higher Ångström exponent values will occur.

5) Non symmetrical errors result in a shift of the maximum of the Angström exponent distribution. If the relative error is larger at the shorter wavelength or at the longer wavelength then the maximum shifts towards the higher values of the Ångström exponent distribution or vice versa.

6) Non symmetrical errors result in a AE-distribution with skewness whereas positive or negative skewness depends on the relative error at the shorter and at the longer wavelength, respectively. If the relative error at the shorter wavelength is larger then at the longer wavelength the Ångström exponent distribution is negative skewed (negative skewness) and vice versa.

7) The Ångström exponent distribution is less symmetric (higher skewness) when the AOD distribution is narrow and more symmetric for a wide AOD distribution. The reason is again due to the fact that the higher portion of larger AOD values corresponds to smaller relative errors.

8) Calculations with identical relative errors but different underlying Ångström exponents give the same shift of the maximum and the same shape of the AE distribution. Therefore any dependency on the underlying Ångström exponent with respect to the shape and the maximum (or its shift) Ångström exponent distributions does not exist.

\section{Conclusions}

When investigating Ångström exponent frequency distributions it is not only important to have small errors, as one would expect from simple error propagation, but it is also desirable that the relative error $\Delta \tau / \tau$ of the AOD are equal or at least similar for the two wavelengths used to calculate the Ångström exponent. Otherwise a shift of the maximum and a change of the normal distribution which is expected to fit the Ångström exponent distribution will occur.

In order to derive the "true" Ångström exponent it is better to consider measurements of the same aerosol type, i.e. having the same mean size (related with the Ångström exponent), under a variety of different optical depth than frequent measurements with the same AOD values, provided the measurement error is constant. This corresponds respectively to the narrow and wide AOD distributions shown previously. 
When long time series are analyzed in terms of frequency distributions, especially for the case of the Ångström exponent frequency distributions, it is necessary to restrict the analysis to the values of AOD which are sufficiently higher than the correspondent error (compare Fig. 3).

The results of this investigation can be applied to all optical quantities related with Ångström exponents, except for retrievals which are based on an aerosol model. They are not restricted to AOD measurements derived from sun photometer measurements. The obtained results may be of particular relevance whenever a comparison of different Ångström exponents derived from instruments of the same type is needed or a closure study using different instruments and platforms will be performed.

Acknowledgements. This work was supported by Fundação para a Ciência e Technologia under grant SFRH BPD 145082003.

Edited by: G. McFiggans

\section{References}

Ångström, A.: On the atmospheric transmission of sun radiation and on dust in the air, Geogr. Ann., 11, 156-166, 1929.

Ångström, A.: On the atmospheric transmission of sun radiation II, Geogr. Ann., 12, 130-159, 1930.

Ångström, A.: Techniques of Determining the Turbidity of the Atmosphere, Tellus, 13, 214-223, 1961.

Ångström, A.: The parameters of atmospheric turbidity, Tellus, 16, 64-75, 1964.

Cachorro, V. E., Romero, P. M., Toledano, C., Cuevas, E., and de Frutos, A. M.: The fictitious diurnal cycle of aerosol optical depth: A new approach for "in situ" calibration and correction of AOD data series, Geophys. Res. Lett., 31, L12106, doi:10.1029/2004GL019651, 2004.

Campanelli, M., Estellés, V., Tomasi, C., Nakajima, T., Malvestuto, V., and Martínez-Lozano, J. A.: Application of the SKYRAD Improved Langley plot method for the in situ calibration of CIMEL Sun-sky photometers, Applied Optics, 46 (14), 26882702, 2007.

Eck, T. F., Holben, B. N., Reid, J. S., Dubovik, O., Smirnov, A., O'Neill, N. T., Slutsker, I., and Kinne, S.: Wavelength Dependence of the Optical Depth of Biomass Burning, Urban, and Desert Dust Aerosols, J. Geophys. Res., 104(D24), $31333-$ $31349,1999$.

Fröhlich, C. and Anklin, M.: Uncertainty of total solar irradiance: an assessment of the last twenty years of space radiometry, Metrologia, 37, 387-391, 2000.

Gobbi, G. P., Kaufman, Y. J., Koren, I., and Eck, T. F.: Classification of aerosol properties derived from AERONET direct sun data, Atmos. Chem. Phys., 7, 453-458, http://www.atmos-chemphys.net/7/453/2007/, 2007.

Gong, S. L.: A parameterization of sea-salt aerosol source function for sub- and super-micron particles, Global Biogeochem. Cy., 17(4), 1997, doi:10.1029/2003GB002079, 2003.

Hamonou, E., Chazette, P., Balis, D., Dulac, F., Schneider, X., Galani, E., Ancellet, G., and Papayannis, A.: Characterization of the vertical structure of Saharan dust export to the Mediterranean basin, J. Geophys. Res., 22 257-22 270, 1999.
Holben, B. N., Eck, T. F., Slutsker, I., Tanre, D., Buis, J.P., Setzer, A., Vermote, E., Reagan, J. A., Kaufman, Y. J., Nakajima, T., Lavenu, F., Jankowiac, I., and Smirnov, A.: AERONET A Federated Instrument Network and Data Archive for Aerosol Characterization, Remote Sens. Environ., 66, 1-16, 1998.

Ignatov, A., Stowe, L., and Singh, R.: Sensitivity study of the Angstrom exponent derived from AVHRR over the Oceans, Adv. Space Res., 21(3), 439-442, 1998.

Kaskaoutis, D. G. and Kambezidis, H. D.: Comparison of the Ångström parameters retrieval in different spectral ranges with the use of different techniques, Meteorol. Atmos. Phys., accepted, 2008.

Knobelspiesse, K. D., Pietras, C., Fargion, G. S., Wang, M., Frouin, R., Miller, M. A., Subramaniam, A., and Balch, W. M.: Maritime aerosol optical thickness measured by handheld sun photometers, Remote Sens. Environ., 93, 87-106, 2004.

O'Neill, N. and Royer, A.: Extraction of bimodal aerosol-size distribution radii from spectral and angular slope (Angstrom) coefficients, Appl. Optics, 32(9), 1642-1645, 1993.

O’Neill, N. T., Ignatov, A., Holben, B. N., and Eck, T. F.: The lognormal distribution as a reference for reporting aerosol optical depth statistics; Empirical tests using multi-year, multi-site AERONET sun photometer data, Geophys. Res. Lett., 27(20), 3333-3336, 2000.

Remer, L. A., Kaufman, Y. J., Tanre, D., Mattoo, S., Chu, D. A., Martins, J. V., Li, R.-R., Ichoku, C., Levy, R. C., Kleidman, R. G., Eck, T. F., Vermote, E., and Holben, B. N.: The MODIS Aerosol Algorithm, Products and Validation, J. Atmos. Sci., 62(4), 947-973, 2005.

Smirnov, A., Holben, B. N., Savoie, D., Prospero, J. M., Kaufman, Y. J., Tanre, D., Eck, T. F., and Slutsker, I.: Relationship between column aerosol optical thickness and in situ ground based dust concentrations over Barbados, Geophys. Res. Lett., 27(11), 1643-1646, 2000.

Smirnov, A., Holben, B. N., Eck, T. F., Dubovik, O., and Slutsker, I.: Effect of wind speed on columnar aerosol optical properties at Midway Island, J. Geophys. Res., 108(D24), 4802, doi:10.1029/2003JD003879, 2003.

Tahnk, W. R. and Coakley Jr., J. A.: Aerosol optical depth and direct radiative forcing for INDOEX derived from AVHRR: Observations, January-March 1996-2000, J. Geophys. Res., 107(D19), 8010, doi:10.1029/2000JD000183, 2002.

Verein Deutscher Ingenieure VDI: Environmental Meteorology: Measurements of the Atmospheric Turbidity Due to Aerosol Particles with Sunphotometers, VDI 3786, 32 pp., 1994.

Voss, K. J., Welton, J. E. J., Quinn, P. K., Frouin, R., Miller, M., and Reynolds, R. M.: Aerosol optical depth measurements during the Aerosols99 experiment, J. Geophys. Res., 106(D18), $20811-$ 20 819, 2001.

Wai, K.-M. and Tanner, P. A.: Wind-dependent sea salt aerosol in a Western Pacific coastal area, Atmos. Environ., 38, 1167-1171, 2004.

Wehrli, C.: Interactive comment on "Some considerations about Ångström exponent distributions" by F. Wagner and A. M. Silva, Atmos. Chem. Phys. Discuss., 7, S4527-S4528, 2007.

Zhang, K. M., Knipping, E. M., Wexler, A. S., Bhave, P. V., and Tonnesen, G. S.: Size distribution of sea-salt emissions as a function of relative humidity, Atmos. Environ., 39, 3373-3379, 2005. 